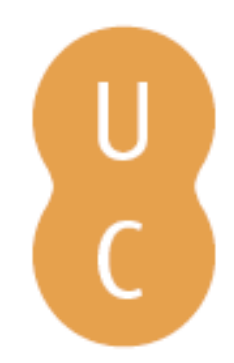

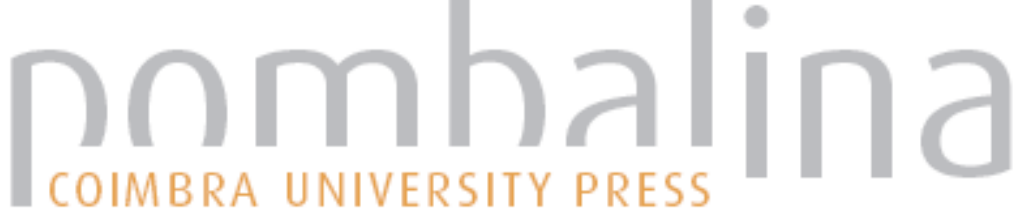

\section{Important features of talent coachers for talent development in sports}

Autor(es): $\quad$ Ark, Mathijs van; Elferink-Gemser, Marije T; Roskam, Ad; Visscher, Chris

Publicado por: Imprensa da Universidade de Coimbra

URL

persistente: URI:http://hdl.handle.net/10316.2/31714

DOI: $\quad$ DOI:http://dx.doi.org/10.14195/978-989-26-0506-7_12

Accessed : $\quad$ 26-Apr-2023 10:48:15

A navegação consulta e descarregamento dos títulos inseridos nas Bibliotecas Digitais UC Digitalis, UC Pombalina e UC Impactum, pressupõem a aceitação plena e sem reservas dos Termos e Condições de Uso destas Bibliotecas Digitais, disponíveis em https://digitalis.uc.pt/pt-pt/termos.

Conforme exposto nos referidos Termos e Condições de Uso, o descarregamento de títulos de acesso restrito requer uma licença válida de autorização devendo o utilizador aceder ao(s) documento(s) a partir de um endereço de IP da instituição detentora da supramencionada licença.

Ao utilizador é apenas permitido o descarregamento para uso pessoal, pelo que o emprego do(s) título(s) descarregado(s) para outro fim, designadamente comercial, carece de autorização do respetivo autor ou editor da obra.

Na medida em que todas as obras da UC Digitalis se encontram protegidas pelo Código do Direito de Autor e Direitos Conexos e demais legislação aplicável, toda a cópia, parcial ou total, deste documento, nos casos em que é legalmente admitida, deverá conter ou fazer-se acompanhar por este aviso. 
Manuel J. Coelho e Silva António J. Figueiredo Marije T. Elferink-Gemser Robert M. Malina Editors
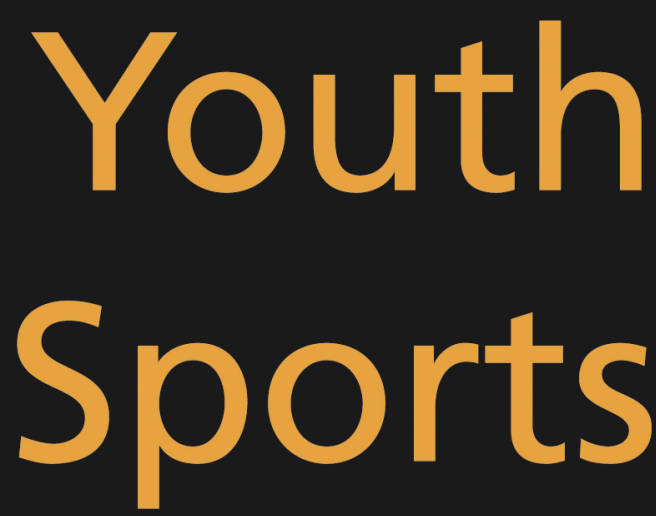

\section{Growth, Maturation and Talent}




\title{
EDIC̣̃̃o
}

Imprensa da Universidade de Coimbra

Email: imprensauc@ci.uc.pt

URL: http://www.uc.pt/imprensa_uc

Vendas online: http://www.livrariadaimprensa.com

\section{CONCEPÇÃO GRÁFICA}

António Barros

\section{EXECUÇÃO GRÁFICA}

\author{
Norprint
}

ISBN

978-989-26-0005-5

\section{DEPÓSITO LEGAL}


Manuel J. Coelho e Silva António J. Figueiredo Marije T. Elferink-Gemser

Robert M. Malina

Editors
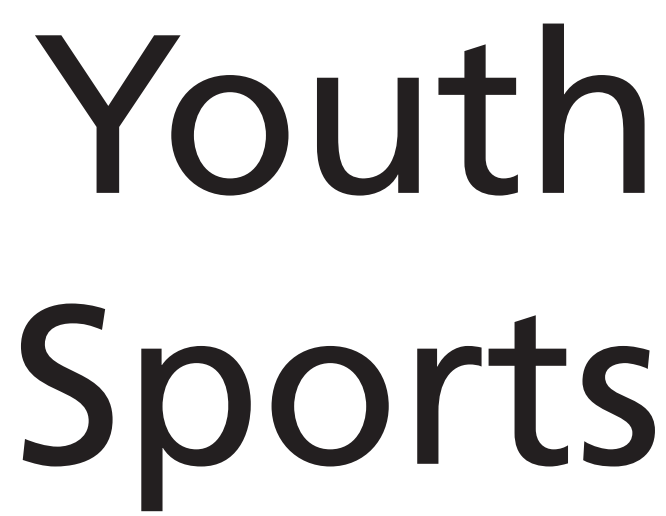

Growth, Maturation and Talent

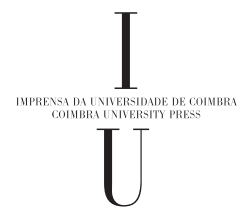


Part 3:

TRAINING 


\title{
CHAPTER 12: IMPORTANT FEATURES OF TALENT COACHES FOR TALENT DEVELOPMENT IN SPORTS
}

\author{
Mathijs van Ark \\ Marije T Elferink-Gemser \\ Ad Roskam \\ Chris Visscher
}

\section{INTRODUCTION}

Elite sports have a vast importance in society, have much attention in the media, and a lot of money is involved. As a consequence, the development of talented athletes in sports is becoming a big issue nowadays. A talented athlete can be defined as an athlete who performs better than his or her peers during training and competition, and who has the potential to reach elite level (Howe et al., 1998; Helsen et al., 2000, Elferink-Gemser et al., 2004). More and more it is realized that talent development plays an important role in reaching elite level in sports and excelling at this level (Singer and Janelle, 1999, Williams and Reilly, 2000, Ericcson, 2003). Talent development is influenced by multiple factors; a successful interaction of biological, psychological, and sociological factors is needed for the development of expertise in sport (Baker et al., 2003). One of the important factors for talent development is the coach of a talented athlete (talent coach) (Singer and Janelle, 1999, Baker et al., 2003, Gould et al., 2002). A coach's degree of knowledge and skills in many areas affect the performance of an athlete (Abraham et al., 2006). Six features with which a talent coach can contribute to the development of a talented athlete are outlined below.

The first features which are important for a talent coach are his experience and education. One of the important ways to learn the profession of coaching is by experience. Previous experiences as a player, assistant coach, or an instructor provide a coach with (sport-specific) knowledge about the sport in which the coach is functioning (Lemyre et al., 2007). The level of education of a coach seems to be an important characteristic as well. Several studies have demonstrated that elite coaches are more likely to have a higher level of education (Lyle, 2002). For example, Gould et al. (1990) found that a large percentage of elite U.S. national team, Pan American, and Olympic coaches have a high education (78\% has a Bachelor degree or higher). 
The synchronization of the role of the coach with developmental stages of an athlete is a second feature with which a talent coach can contribute to the development of a talented athlete. Talent is a dynamic concept and factors which form a talent do not only interact, but also change over time (Abbott et al., 2005). Several authors have phrased stages through which talented athletes progress over time (Bloom 1985, Côté 1999, Balyi et al., not dated). The cognitive, physical, and emotional needs of children change at the various stages of their sport participation. Due to these changes it is important that the role of coaches change accordingly (Côté et al., 2003). Martindale et al. (2007) also confirm the importance of emphasis on appropriate and ongoing development (not on early success).

A third important way in coaching talented athletes is goal setting. Despite some contradiction in the literature, the current opinion about goal setting is that it is beneficial in the sports domain (Kyllo and Landers, 1995, Mooney and Mutrie, 2000, Weinberg et al., 200I, Martindale et al., 2007). Skills are better acquired and maintained when goals are set than when performers are instructed to only do their best in sports participation (Boyce, 1992). Martindale et al. (2007) also stresses goal setting as one of the important generic characteristics of effective talent development environments (in direct process of coaching).

A fourth feature is the motivational climate implicated by a talent coach. Abbott and Collins (2004) conclude in their review that it is not the performance at a young age of a talented athlete that is a good indicator of eventual attainment in a sport. In contrast, motivation and appropriate learning strategies appear to be more important in order to fully develop one's potentials. Motivation of an athlete is associated with the motivational climate (Ntoumanis and Biddle, 1999). The coach of an athlete was found to have an important role in constructing the motivational climate (Pensgaard and Roberts, 2002). An often used distinction in motivational climates is the distinction between mastery climate and performance climate (Dweck, 1999). In a performance climate the athlete's perceived success and competence is based on performance compared to others (win/lose). A performance climate is created when the coach promotes intra-team rivalries, favours the most talented players, and punishes players for making mistakes. In contrast, athletes with a mastery based motivation feel successful on a self-referenced basis. A mastery climate is created by a coach when athletes are encouraged to focus on their own personal development (Cumming et al., 2007).

The degree of autonomy supportive behaviour exhibited by the talent coach is a fifth feature. Autonomy supportive behaviour can be defined as 'a coach who takes the athlete's perspective, acknowledges the athlete's feelings and provides him with pertinent information and opportunities for choice, 
while minimizing the use of pressures and demands' (Black and Deci, 2000, p. 742). Conversely, a coach can also exhibit controlling behaviours, which are defined as 'pressures to think, feel or behave in specified ways, thereby ignoring an athlete's needs and feelings' (Mageau and Vallerand, 2003, p. 886). By exhibiting autonomy-supportive behaviours coaches can influence important aspects for a talented athlete to reach elite level (Mageau and Vallerand, 2003).

Finally, a talent coach also has to take into account external influences, since the athlete's relationships with significant others are important to their successes (Morgan and Giacobbi, 2006). The family and especially the parents play an important role in the development of a talented athlete (Côté, 1999). Most parents positively influence the development of their child, a number of parents also exist who unknowingly interfere with their child's development (Gould et al., 2006).

The studies mentioned above investigated important features for talent coaches. However, these studies focused only on one aspect with which a talent coach can contribute to the development of talented athletes. In contrast, this research strives to give a more complete overview on all features mentioned of talent coaches with which they can contribute to the development of a talented athlete. To our knowledge, no such research is conducted before, with exception of a study by Martindale et al. (2007). They investigated talent development environments from the elite youth coach perspective and phrased five main generic characteristics for effective talent development environments: I) long-term aims and methods; 2) wide-ranging coherent messages and support; 3) emphasis on appropriate development, not early success; 4) individualized and ongoing development; and 5) integrated, holistic and systematic development. To extend upon Martindale et al.'s research, the current research focuses on more specific features of talent coaches. These specific features may help in the selection and/or training of talent coaches.

The first part of this research consists of interviews with top level Dutch talent coaches to reveal which features are important for talent coaches in the development of talented athletes. It is assumed that these coaches possess and exhibit the right features for the development of talented athletes. In the second part of this study, it is investigated if these apparent features can be linked to degree of successfulness of a talent coach. To our knowledge features of talent coaches have never been linked directly to a degree of successfulness before. To establish successfulness, the eventual level (at senior age) of talented athletes coached by talent coaches is used. 
Consequently, the purpose of the first part of this research is to find out which specific features top level talent coaches possess. The purpose of the second part of this research is to find out which of these features are linked to the degree of successfulness of a talent coach.

\section{PART I}

\section{Methods}

The sample consisted of nine top level Dutch talent coaches $(8$ male and I female) from different sports: 5 individual and 4 team sports. Sports included are sports in which Dutch athletes compete with the best countries in the world: swimming, speed-skating, athletics, tennis, judo, soccer, volleyball, handball and field hockey. The top level talent coaches were selected by the national sport association in cooperation with the Dutch Olympic committee (NOC*NSF). The top level talent coaches were selected on the following criteria: 1) coaching highest level youth (aged 15-20 years), 2) coached multiple talents who reached elite level in the past, 3) at least 5 years of experience as a talent coach, and 4) head coach of athlete(s) (not only a coordinating role). All talent coaches coach at least one Dutch national team in the age category of 16 to around 20 years at the moment. Coaching is their main occupation for at least 3 years. Seven talent coaches coach and/or train a group of talented athletes almost daily, 2 talent coaches coach their group of talented athletes less frequently, because their athletes train and play games at their clubs.

The participants were contacted by telephone and after a short clarification of the study, they were asked to cooperate with an interview concerning coaching of talented athletes. All participants agreed to participate. A convenient time was scheduled for the interview at a location requested by the talent coaches. In most cases this was the working place or a canteen near the training venue of the participant. The procedures were in accordance with the medical ethical standards of the University of Groningen.

First, the interviewer shortly explained the purpose of the study and then asked permission to audiotape the interview. Subsequently, the participants were told the processing of the interview would occur anonymously. A semi-structured interview guide was constructed in line with a deductively constructed set of features with which a talent coach can contribute to the development of a talented athlete. Therefore, the interview guide comprised six main sections (education \& experience, synchronization with developmental stages, goal setting, implementation motivational climate, autonomy supportive behaviour, and considering significant others). On every 
feature a set of questions was constructed in order to reveal the way in which the participants coached in this area. The first question on every theme was a general question concerning the theme. Follow up questions were asked on specific parts of the features. In the end, the participants were asked which characteristics of a good talent coach were important in their opinion. Finally, the participants were asked to distribute 100\% over the six features from the set of important features of talent coaches, attributing higher percentages to more important features. Questions on every theme were carefully constructed based on literature and effort was made to gain honest openended responses (Foddy, 1993). A pilot interview was accomplished in order to examine the interview guide. Furthermore critical appraisal of experts with domain related knowledge was used to evaluate and refine the interview questions.

The audio recordings of the interviews were transcribed completely. Both deductive and inductive approaches were used to analyse the data. First an initial set of features was constructed deductively. Subsequently, inductive analysis of the interviews lead to a revision of the initial set of features (insertion and/or deletion of features). This method of analyzing data is based on a form of concept driven coding: template analysis (King, 1998).

\section{$\underline{\text { Results }}$}

Table I shows the initial set of features and sub features with which a talent coach can contribute to the development of a talented athlete derived deductively.

Table I. Initial set of features with which a talent coach can contribute to the development of a talented athlete

\begin{tabular}{lll}
\hline Education and experience & - & Education \\
& - & Experience as athlete \\
& - & Experience as coach \\
Synchronization with developmental stages & - & Development from guidance and support of coach in early years to \\
& & responsibility shift from coach to individual in later years. \\
Goal setting & & \\
& - & Short \& long term \\
& - & Explicit \\
& &
\end{tabular}

(continues) 
(continuation)

$\begin{array}{lll}\text { Motivational climate } & & \\ & - & \text { Focusing on development athlete not outcome games } \\ & - & \text { Not punishing athletes for making mistakes } \\ \text { Autonomy supportive behaviour } & - & \text { Not favouring most talented athletes } \\ & - & \text { Involving athlete in training and development } \\ & - & \text { Acknowledging an athlete's feelings and perspectives } \\ \text { Considering significant others } & - & \text { Providing pertinent information and opportunities for choice } \\ & - & \text { Independence athlete } \\ & - & \text { Minimizing use pressures and demands } \\ & - & \text { Involving \& informing parents } \\ & & \text { Role model }\end{array}$

a) Education and experience

Six talent coaches have a Bachelor degree or higher. Five talent coaches have accomplished a college education that is related to sport. All talent coaches accomplished the highest sport specific coach education in their sport. Six of them also possess, are attending, or are planning to attend the highest coach education of the Dutch Olympic Committee (NOC*NSF). All talent coaches participated in their sport as well, seven talent coaches performed at national level in their sport and two performed at an international level. The mean years of coaching experience by the talent coaches is 19,7 years (SD = 7,6). Seven talent coaches coached every age group. The two others did not coach respectively athletes younger than 14 and 16 years old. All but one of the participants said they did participate in activities to acquire extra knowledge. One talent coach did not participate in extra courses due to lack of time. Activities to acquire more knowledge in which the talent coaches participated were: giving lectures/courses themselves $(n=6)$, attending sport alliance organised extra courses $(n=5)$, attending courses organised by NOC*NSF $(n=5)$, visiting conferences $(n=2)$, and extra education in management $(n=1)$.

\section{b) Synchronization with developmental stages}

All but one of the talent coaches indicated a scale from a more leading style of coaching in younger years of athletes to more independent athletes and only guiding them when they grow older. One talent coach for example stated that he asks a lot of discipline from younger athletes as an investment for later years, because then it is easier for them to take care of themselves when they grow older. A quote of a talent coach with another example in which this is indicated is presented below. 
"As the talented athlete grows older, my style of coaching changes from leading through guiding between certain boundaries to supervision. The pace of this development (from leading to supervision) varies from one talented athlete to another."

Eight talent coaches stated that besides current performance, they take into consideration the potential development in selecting athletes. For example, talent coaches take the development of anthropometric characteristics, amount of training accomplished by an athlete in the past and anthropometric characteristics of parents into consideration when selecting talented athletes. The following quote provides an example that underlines the importance of taking into consideration potential development when selecting talented athletes.

"Of course you consider time (at for example 100 meters) when selecting talented athletes. Time is a tangible fact. But then you also consider how the time is realized."

All but one of the talent coaches coached athletes of the same age differently because of different characters of the athletes. A talent coach for example stated that every child is different, therefore he coaches every talented athlete in a different way. Three talent coaches stated that they take into consideration the physical load possible in a developmental stage of an athlete. For example, a talent coach stated that he decreased the amount of training a lot because of the possible load for the knee-joint in the growth spurt of a particular athlete. A quote of a top level talent coach which supports the different approach of different athletes is shown below.

"Each talented athlete is unique and needs his own approach."

c) Goal setting

In both team sports as well as individual sports, talent coaches reported that group goals are formulated. All talent coaches also indicated that individual goals per athlete are set. An example of a quote of a talent coach which indicates this is presented below.

"The goal of the Dutch National youth selection is to reach the World Championships. From this overall goal I detract the individual goals."

All talent coaches reported that long as well as short term goals are set. Main goals are formulated for a long term; these goals have sub-goals which are 
further elaborated in execution goals. One talent coach for example stated that rough goals are formulated for a number of years, concrete goals for one year and the goals are elaborated per month. A quote of a talent coach which provides another example of how goals for different terms are set is shown below.

"The personal development plan (PDP) states the individual goals for the period of one year together with some intermediate goals. Teamgoals are being formulated for half of a season and the goals for each match on a weekly basis. Furthermore, every Monday I outline the goals for that week and at the beginning of every training I tell them the goals for that specific day."

Eight talent coaches record the goals. One talent coach only explicitly stated the goals, but would have recorded goals in case he coached a team with which he would work on a daily basis. Three talent coaches for example record goals per athlete in a document called Personal Development Plan. All talent coaches reported that goals are formulated in consultation with coach and athlete. Seven explicitly stated that goals are initially formulated by their athletes. A quote of a talent coach with which this is indicated is presented below.

"We make a Personal Development Plan (PDP) for each player. In this plan the player formulates his own goals first and then we add the goals which we have for this specific player. We review the PDP every three months along with the player."

The talent coaches indicated that goals were set on several areas. The following areas in which goals are set were listed the most: physical $(n=6)$, technical $(n=5)$, cautious with performance $(n=3)$, performance $(n=3)$, organization of daily activities $(n=3)$ and mental $(n=3)$ goals.

\section{d) Motivational climate}

Eight talent coaches stated that development of a talented athlete to elite national team level is most important. A talent coach for example stated that the ultimate goal of a coach of a national youth team is not winning the Youth European or World Championships, but the ultimate goal is to prepare as much athletes as possible for the elite national team. Five talent coaches indicated that they focus more on the process (things to do well in a contest) than the outcome of a contest. A quote with which a talent coach indicated the importance of development of talented athletes is presented below. 
"We always coach toward performance and never toward results. My players are being trained to want to play well instead of wanting to win. We use the verb 'to win' very little."

Although the outcome of contests is less important, three talent coaches explicitly stated that contests are definitely important for the development of a talented athlete. One talent coach for example compared the relationship between winning contests and development to the question: which came first, the chicken or the egg? A quote from which it appeared that contests are important as well is shown below.

"In the end, you train youthful athletes for long term performance. In fact, I consider developing athletes as providing them with a good education to the maximum of their potential but, of course, when you participate in an European Youth Championship, you very much live in that moment, that is when you need to perform. You work toward that goal, but experiencing it is a part of the learning process as well. In that respect these issues are two separate ones."

The importance of cooperation within a group of talented athletes is stated to be important by seven talent coaches. Some contradiction exists between the talent coaches in the application of intra-team rivalries. Some talent coaches $(n=3)$ indicated that they apply intra-team rivalries, while others $(n=2)$ indicated that they do not. Four talent coaches stated that they apply intrateam rivalries now and then, but intra-team rivalries have to be applied with care. One talent coach for example stated that rivalry between two athletes must lead to an improvement of both athletes. A quote which indicated that intra-team rivalries are applied with care is presented below.

"In the end you have to get the best players within the National Team. Rivalry is always an issue within the National Team and I consider it positive because it improves players. But you have to be careful that it (rivalry) doesn't become too dominant, that is when the coach has to interfere. Though, I believe that some rivalry is part of top sports."

The talent coaches use punishments and rewards differently. Most talent coaches $(n=5)$ face athletes with their mistakes, four talent coaches indicated that they explain athletes why they did something right or wrong. Two talent coaches stated that they punish athletes by letting them do something non favourable, for example putting away the equipment, when they loose in a training. In contrast, four talent coaches indicated that they incidentally use punishment when athletes make mistakes. 
Seven talent coaches indicated that they try to give athletes an equal amount of attention. Three talent coaches indicated that athletes get less attention when they do not put in effort themselves. The next quote is an example of a talent coach who indicated this.

"I pay an equal amount of attention to everyone, however, they have to deserve it by living as a professional. If anyone shows less effort, he also gets less attention."

\section{e) Autonomy supportive behaviour}

All talent coaches involve athletes in their development, for example by letting them formulate their own goals or constructing a personal development plan per athlete. Seven talent coaches explicitly stated that goals are initially formulated by the talented athletes themselves. One talent coach tried to increase the consciousness of his talented athletes as well by letting them fill in a self evaluation form. Eight talent coaches provide a talented athlete with opportunities for choice. A talent coach for example outlined the consequences of moving closer to or further away from a training venue to a talented athlete. A quote by which a talent coach indicated that he provides athletes with consequences of choices is outlined below.

"You talk about the future with the athlete. At this moment, for example, we talk about next year. Then I ask the athlete what he wants and I present him the consequences and we discuss these together."

All talent coaches indicated that they try to increase the independence of their athletes in one way or the other. Three talent coaches explicitly stated that they give responsibilities to the talented athletes. One talent coach for example stated that enhancing independence is a high priority because athletes must be able to make their own decisions when they become adults. A quote in which this is stated is shown below.

"Independence starts with little things, for example that you make them responsible for bringing the equipment with them or being on time somewhere."

The feelings of talented athletes are taken into consideration by all talent coaches. It is implicitly stated by the talent coaches that they take an athlete's perspective. One talent coach for example, stated that he sometimes feels like a coach, father, mother, brother, and trainer of an athlete at the same time. Another talent coach stated that when an athlete does not feel happy, an 
athlete can not achieve an optimal performance. A coach therefore needs to adjust to the feelings of an athlete. An example of a quote in which it is stated that feelings of talented athletes have to be considered is presented below.

"You can attain very much if you are able to connect with people in the right way in order to direct them. It is important to deal with the emotions of the athletes to accomplish this."

No relevant statements were found in the data on the sub feature 'minimizing use of pressures and demands'.

\section{f) Considering significant others}

Most talent coaches $(n=6)$ explicitly stated that they inform parents of talented athletes, but they do not want parents to interfere and wish that parents distance themselves more from their child. One talent coach for example stated that he realized that parents are a huge sponsor in the youth of an athlete, therefore he explains for example the training schedule to them. Another talent coach stated that he involves parents in practical things but does not involve them in the content of a training for example. The following quote of a talent coach indicated a way of involving parents of talented athletes.

"With the Dutch National Youth Selection we always organize special days for parents prior to the season and before big tournaments in order to inform them about what it takes to become a top level athlete... I try to involve parents a lot, but I also try to teach them to let their children go."

Furthermore the talent coaches $(n=3)$ indicated that parents can always come to them when they have a question. All talent coaches take into consideration the importance of education for the talented athletes. Two talent coaches for example stated that athletes need to realize that only a very small number of athletes earn such an amount of money during their elite sport career that they do not have to work anymore, therefore education is essential. Another example is the following quote of a talent coach.

"It is only possible to complete a programme as a top level athlete if one combines it with education. Education prepares you for the rest of your life where sport does not." 
Three talent coaches reported that a social life is important as well, it is indicated that a balance between sport and social life is needed. An example of a quote with which this is indicated by a talent coach is shown below.

"You don't have a social life? No? Then we have to arrange one, a year without a social life is impossible, let's arrange that you can party those two weekends after the game... and relax"

All talent coaches use role models of athletes in one way or the other to motivate talented athletes. A talent coach for example showed videos of elite level games and explained why they performed at that level. Another example of a quote of a talent coach in which the use of role models is indicated is presented below.

"It is very easy to compare yourself to those who perform less but then I tell them to look at top-class athletes and they come to very different conclusions."

The largest part of the initial set of features with which a talent coach can contribute to the development of a talented athlete is in agreement with statements of the talent coaches. All main features remained intact and the largest part of the sub features did not change either (see table 2).

Only one new feature was indicated by more than two talent coaches $(n=3)$ in their answers to the question 'what do you think are important features for a good talentoach?'. This was, 'knowing which qualities a talented athlete has'. It was also stated by the talent coaches that they take into consideration characters of athletes, this bears some resemblance with knowing which qualities an athlete has, therefore these issues were added to the set of features together in the new sub feature 'know and take into consideration qualities and characters of different athletes' as part of the feature 'synchronization with developmental stages'. Another sub feature added to the feature synchronization with developmental stages was 'take into consideration physical load possible', because top level talent coaches also stated that they take into consideration the changing physical load possible in various developmental stages. Two sub features were deleted from the feature 'motivational climate': 'no intra-team rivalries' and 'not punishing athletes for making mistakes'. These sub features were deleted because of contradictory statements by the talent coaches on these subjects. The sub feature 'minimizing use of pressures and demands' was deleted from the feature 'autonomy supportive behaviour', because no relevant statements on this sub feature were found in the data. The sub feature 'involving and informing parents' from the feature 'considering significant others' was adapted to 'informing parents' because talent coaches stated that they did inform 
parents but did not want them to become to much involved. Furthermore, top level talent coaches stated that they took into consideration school and social life of a talented athlete, therefore 'take into consideration school and social life' was added as a sub feature.

Table 2. Final set of features with which a talent coach can contribute to the development of a talented athlete

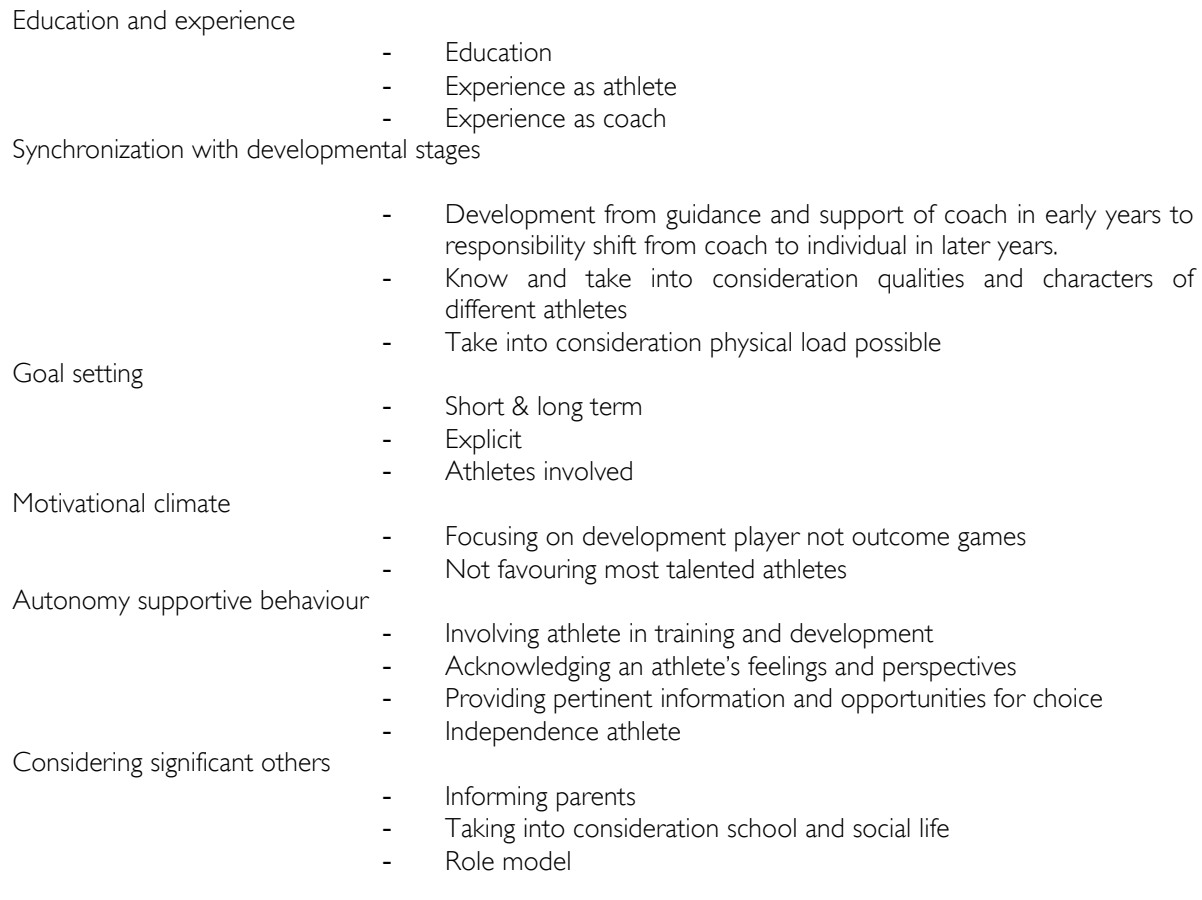

The talent coaches stated that it was difficult for them to answer the final question 'distribute 100\% over the six features important for talent coaches, attributing higher percentages to more important features'. Although they stated it was difficult, they indicated that 'synchronization with developmental stages' was the most important feature and 'considering significant others' was stated to be the least important one. 


\section{PART 2}

\section{Method}

The sample consisted of talent coaches ( $n=14 ; 13$ males and I female) who coached highest level youth club teams ( $14-20$ years old) of two soccer clubs and two field hockey clubs of the highest national competition level for at least 2 seasons in the period 2000-2005.

After a short clarification of the study, the participants were asked to cooperate with an interview with regard to coaching of talented athletes in their teams of the concerning clubs during the period 2000-2005. The procedures were in accordance with the medical ethical standards of the University of Groningen.

First, it was determined which athletes (14-19 years old) the talent coaches coached during the period 2000-2005 from the two field hockey clubs and the two soccer clubs. Lists of these athletes were displayed to the talent coaches before the interview started.

Subsequently, it was determined which of the talented athletes born in 1988 (currently 19 years or older) reached national top level in their sport at present. National top level is defined as premier league in field hockey and premier league or first division in soccer. This data was used to calculate a degree of successfulness of a talent coach. As a measure for degree of successfulness a percentage is computed. The formula presented below computes a coach's percentage of coached talented athletes reaching top level in their sport.

\footnotetext{
Successfulness $=$

$\sum$ years coach of a talented athlete who reached top level

$\sum$ years coach of all talented athletes
}

Figure I. Formula for calculating a coach's percentage of talented athletes coached who reached top level

First, the interviewer shortly explained the purpose of the study; subsequently the participants were told the processing of the interview would occur anonymously. A structured quantitative interview guide was constructed in line with available literature and part I of this research. This interview provided scores on the several apparent important features of a talent coach with 
which he contributed to the development of a talented athlete. The scores were based on several questions concerning a specific feature.

A score on the feature 'education and experience' was obtained by calculating a mean score on five items. Rank scores from 1-I0 were established on every item, a score of I represented the lowest level of education or experience and a score of 10 represented the highest level of education or experience. The five items were: level of education, level of education in coaching, years of coaching, number of age categories coached, and highest level participated in as an athlete.

A score on the feature 'considering developmental stages' was obtained by calculating the mean score on 6 items. Talent coaches had to provide a score from I-10 on every item. A score of I represented not at all considering developmental stages and a score of 10 represented totally considering developmental stages. The items were: I) to what extent did you coach more on encouraging autonomy when athletes grow older, 2) to what extent did you coach more on encouraging responsibility when athletes grow older, 3) to what extent did you coach more on encouraging consciousness when athletes grow older, 4) to what extent did you coach more on encouraging involvement in an athlete's own development when athletes grow older 5) to what extent did you consider physical development between athletes, and 6) indicate on a scale from regarding current level (I) to potential development (I0) which factor was more important in selecting talented athletes.

A score on the feature 'goal setting' was obtained by calculating the mean score on 3 items. The 3 items were: I) indicate $(1-10)$ how often talent coaches set short and long term goals ( 1 = never, $10=$ always), 2$)$ which percentage of the goals were written down (score is the percentage divided by $10,10 \%$ or lower represented a score of 1 ), and 3) which percentage of the goals were initially formulated by athletes (score is the percentage divided by $10,10 \%$ or lower represented a score of $(1)$.

A score on the feature 'motivational climate' was obtained by calculating the mean score on 3 items. Talent coaches were asked to provide an indication on a 10-point scale. A score of I represented an indication of a performance climate and a score of 10 represented an indication of mastery climate. I) Indicate on a scale from importance of outcome contests (I) to importance of playing well (10) on which aspect you focused before and during games, 2) Indicate on a scale from importance of winning (I) to importance of learning new things (10) on which aspect you focused more during a season, and 3 ) indicate on a scale from favouring more talented 
athletes (I) to favouring every athlete for an equal amount (I0) what you do more.

A score on the feature 'autonomy supportive behaviour' was obtained by calculating the mean score of 7 items. Talent coaches had to provide a score from I-I0 on every item, a score of I represented not at all exhibiting the autonomy supportive behaviour and a score of 10 represented totally exhibiting the autonomy supportive behaviour. The items were: I) to what extent do you try to enhance a talented athlete's autonomy, 2) to what extent do you try to enhance a talented athlete's responsibility, 3) to what extent do you involve a talented athlete in his development, 4) to what extent do you try to enhance a talented athlete's consciousness of one's own development, 5) to what extent do you take into account feelings of an athlete by altering the training schedule, 6) to what extent do you take into account feelings of an athlete by altering the way of approaching athletes, and 7) to what extent do you provide consequences of choices for the careers of athletes.

A score on the feature 'considering significant others' was obtained by calculating the mean score on 3 items. Talent coaches had to provide a score from I-I0 on every item. A score of I represented not at all considering significant others and a score of 10 represented totally considering significant others. The items were: I) to what extent do you inform parents about their role, 2) to what extent are you informed of and do you take into consideration the school/study of an athlete, and 3) to what extent are you informed of and do you take into consideration the social life of an athlete.

Degree of successfulness and the scores on every feature were computed for every talent coach. Subsequently, Spearman correlation coefficient (rho) was computed between degree of successfulness and the separate features of a talent coach with which he can contribute to the development of a talented athlete. An alpha value of 0,05 (I-tailed) was used to indicate significance. A poor correlation coefficient was defined as rho < 0,3 , a moderate correlation was defined as $0,3<$ rho $<0,6$, a good correlation coefficient was defined as $0,6<$ rho $<0,8$, and an excellent correlation coefficient was defined as rho > 0,8 (Söderman and Malchau, 200I). 


\section{RESULTS}

Table 3 shows the degree of successfulness and scores on the features with which a talent coach can contribute to the development of talented athletes of all talent coaches.

Table 3. Degree of successfulness and scores $(1-10)$ on the six features with which a talent coach can contribute to the development of a talented athlete of the talent coaches. Legend: [DS] degree of successfulness; [EE] education and experience; [SDS] synchronization with developmental stages; [GS] goal setting; [IMC] implementation of motivational climate; [ASB] autonomy supportive behaviour; [CSO] considering significant others

\begin{tabular}{cccccccc}
\hline $\begin{array}{c}\text { Talent } \\
\text { coach }\end{array}$ & $\begin{array}{l}\text { DS } \\
(\%)\end{array}$ & EE & SDS & GS & IMC & ASB & CSO \\
\hline 1 & 21 & 7.75 & 7.17 & 3.40 & 9.33 & 7.14 & 7.33 \\
2 & 41 & 5.05 & 7.79 & 6.00 & 5.92 & 9.43 & 5.67 \\
3 & 56 & 5.05 & 9.17 & 2.53 & 5.00 & 8.71 & 5.67 \\
4 & 32 & 5.50 & 7.28 & 5.00 & 6.60 & 6.76 & 6.33 \\
5 & 43 & 6.40 & 7.33 & 5.45 & 4.67 & 7.71 & 4.67 \\
6 & 30 & 6.85 & 7.33 & 3.00 & 5.67 & 7.29 & 6.00 \\
7 & 22 & 7.75 & 7.50 & 3.05 & 6.22 & 7.43 & 3.00 \\
8 & 24 & 4.60 & 6.83 & 5.40 & 6.33 & 5.86 & 4.67 \\
9 & 25 & 7.75 & 6.67 & 3.80 & 8.67 & 8.71 & 8.00 \\
10 & 33 & 5.95 & 8.17 & 5.75 & 6.00 & 8.14 & 7.67 \\
11 & 58 & 6.85 & 10.00 & 7.93 & 6.33 & 8.71 & 6.67 \\
12 & 24 & 5.50 & 9.42 & & & & \\
13 & 42 & 5.50 & 8.17 & 4.80 & 9.33 & 8.14 & 7.00 \\
14 & 38 & 6.85 & 7.17 & 4.03 & 5.73 & 8.29 & 8.33 \\
\hline
\end{tabular}

Note: ${ }^{\text {a }}$ A score from this talent coach could not be obtained on this feature. Spearman correlation coefficients (rho) between degree of successfulness and the six features of talent coaches with which they can contribute to the development of talented athletes are presented in table 4. Significant correlations exist between degree of successfulness and synchronization with developmental stages, and between degree of successfulness and autonomy supportive behaviour. 
Table 4. Spearman correlation coefficients (rho) and p-values (I-tailed significance) between the six features of talent coaches with which they can contribute to the development of talented athletes and degree of successfulness $(n=\mid 4)$

\begin{tabular}{lc}
\hline & Degree of successfulness \\
\hline Education and experience & -0.33 \\
& $(0.13)$ \\
Synchronization with developmental stages & $0.51 *$ \\
Goal setting & $(0.03)$ \\
& 0.40 \\
Implementation motivational climate & $(0.09)$ \\
& -0.33 \\
Autonomy supportive behaviour & $(0.12)$ \\
Considering significant others & $0.65 *$ \\
& $(0.01)$ \\
& -0.06 \\
& $(0.42)$ \\
\hline
\end{tabular}

* significant correlation with an alpha of 0,05

\section{DISCUSSION}

Top level talent coaches were highly educated and had much experience as a coach as well as an athlete. The results of the second part showed a moderate negative correlation of $-0,326(p=0,128)$ between the score on education and experience and degree of successfulness. This finding is remarkable because it is contradictory to findings from the first part. Literature supports the results of the first part; several studies have demonstrated that elite coaches are more likely to have a higher level of education (Lyle, 2002). For example, $78 \%$ of elite U.S. national team, Pan American and Olympic coaches have a Bachelor degree or higher (Gould et al., 1990). The importance of experience is supported in the literature as well, one of the ways with which youth sport coaches learn to coach are previous experiences as a player, assistant coach or an instructor (Lemyre et al., 2007).

A possible explanation for the results of part 2 is that scores on education and experience are combined. Therefore a closer look is taken at the several items which comprise the score of education and experience. The score on the item 'highest level participated in as an athlete' stands out (rho = 0,332). It is considerably higher than the score on 'level of education in coaching' (rho $=0,010$ ) and in the opposite direction compared to 'level of education' (rho $=-0,506$ ), 'years of coaching' (rho $=-0,239$ ), and 'number of age categories coached' (rho $=-0,2 \mid 4$ ). From these correlations it appears that the highest level participated in as an athlete provides the strongest association with degree of successfulness. The correlations of the other items are hard to explain considering the results of part I and available literature. 
Interviews with top level talent coaches revealed that they synchronized their coaching role with developmental stages of a talented athlete. Furthermore, top level talent coaches also indicated that synchronization with developmental stages was the most important feature of a talent coach with which he can contribute to the development of talented athletes. The results of the second part of this study are in consistence with this, a moderate correlation ( $r$ o $=0,506$ ) which was significant $(p=0,033)$ was found between degree of successfulness and synchronization with developmental stages.

Top level talent coaches changed their role as a coach from more leading to only guiding athletes (more independent athletes) when athletes grow older. This is for example supported by Bloom (1985) who named three stages: The early years, middle years and later years. In the early years children are involved in fun and playful activities and they rely heavily on the guidance and support of their coach or teacher. The middle years are characterized by children who become more involved in a particular activity and it becomes more serious. Coaches are more technically skilled than at the previous level. During the later years performers become experts in their chosen activity and this activity dominates their lives. According to Bloom, responsibility for training and competition shifts from coaches to the individual in this phase. Approximately similar stages are phrased by Côté (1999), the stages of Côté (1999) are more sensitive to the sport domain and identified by an age range. The corresponding stages with Bloom's stages are respectively: the sampling years (ages 6-12), specializing years (13-15) and investment years (age 16+). In a model of talent development, constructed by Abbott and Collins (2004), the task of a coach differs per development stage. The task of a coach in the sampling, specializing and investment years is respectively caring coach orientation, technical coaching and collaborative coach/athlete decisionmaking.

Top level talent coaches also took into consideration potential development when selecting talented athletes. This parallels with previous research illustrating that emphasis in talent identification should lay on potential development of talented athletes and not on current measures of performance (Abbott et al., 2005).

Furthermore, top level talent coaches took into consideration the character of talented athletes when coaching them. This is consistent with a finding of Gould et al. (2002). They found that the same coaching strategies were not appropriate for each athlete, different athletes required different things from their coaches at different points in their careers. 
Another aspect that was synchronized by the talent coaches was the possible load of talented athletes. This parallels previous research illustrating that the content and amount of training have to be adjusted per developmental stage (Naughton et al., 2000, Wilmore et al., 2008, Balyi et al., not dated). For example, the optimal window of trainability for aerobic capacity occurs at the onset of Peak Height Velocity and the optimal window of trainability for strength is for girls immediately after Peak Height Velocity or at the onset of the menarche, while for boys it is 12 to 18 months after Peak Height Velocity (Balyi et al., not dated). However, also possible physical overload has to be taken into account, because adolescent athletes who experience rapid growth as well as large increases in training volumes may be vulnerable to overuse injuries (Naugthon et al., 2000).

Interviews with top level talent coaches furthermore revealed that top level talent coaches set explicit goals on short- as well as long term with athletes involved in the goal setting process. These results are consistent with results from the second part, a moderate correlation ( $r$ o $=0,396 ; p=0,090$ ) was found between degree of successfulness and goal setting.

Top level talent coaches took care that long as well as short term goals were set. This is supported by Kyllo and Landers (1995), they concluded in their review concerning goal setting in sport and exercise that besides absolute and moderate goals, also combined short- and long-term goals were associated with the greatest effect. To set both short- and long-term goals, was also found to be important by Weinberg et al. (200 I).

Furthermore, top level talent coaches reported the goals. Findings of Weinberg (1994) confirm that goals should be written down.

It was also indicated by top level talent coaches that goals were first formulated by the athletes and finally formulated in consultation between coach and athlete, furthermore individual as well as team-goals were formulated. Literature supports that athletes should be involved in goal setting, it is for example found that goal setting can be improved as a result of involving athletes in goal setting by allowing individuals to participate in goal setting (Kyllo and Landers, 1995). Widmeyer and Ducharme (1997) also found that having input on goals is beneficial for the performance of an athlete.

The interviews with top level talent coaches revealed that a mastery climate tended to be more favourable than a performance climate, although some actions with which one climate is created above the other show contradictory results. Results of the second part are contradictory to this, a negative moderate correlation ( $r$ ho $=-0,334 ; p=0,122$ ) was found. These equivocal results are hard to explain. Literature suggests that a mastery climate 
is beneficial. Young athletes who were coached by coaches who promoted a mastery-involving motivational climate had less anxiety than athletes who were coached by coaches who did not promote a mastery climate (Smith et al., 2007). Additionally, sport enjoyment and positively rating the coach were predicted by a mastery climate in youth sport, while winning percentage is approximately the same in comparison with a performance climate (Cumming et al., 2007). Another piece of support for a mastery climate arises from a physical educating setting, a mastery climate implemented by the teacher positively influences intrinsic motivation and negatively influences amotivation in physical education pupils (Ommundsen, 2007).

A possible explanation of the different results between part 1 and 2 might be the difference in level of talented athletes coached. Talent coaches from the second part of this study might for example have to favour higher talented athletes because not every athlete is as highly talented as the talented athletes in part I. The mentioned literature does not provide information on this aspect, because the participants were mainly recreational.

Interviews with top level talent coaches revealed that they exhibit many autonomy supportive behaviours. Findings of the second part of this study are consistent with this, degree of successfulness is correlated with autonomy supportive behaviour, a good correlation (rho $=0,653$ ) which was significant $(p=0,006)$ was found between degree of successfulness and autonomy supportive behaviour. Literature supports these findings, the research reviewed in Mageau and Vallerand (2003) shows that autonomysupportive behaviours of a coach have a beneficial impact on athlete's intrinsic and self-determined extrinsic motivation, which are important determinants of performance and persistence. Mageau and Vallerand (2003) mention several studies which provide evidence for the autonomy supportive behaviours mentioned in the sub features. Involving an athlete in training and development is for example supported by Boggiano (1998), acknowledging an athletes feelings and perspectives is for example supported by Koestner et al. (1984) and Deci et al. (1994), providing pertinent information and opportunities for choice is for example supported by Cordova and Lepper (1996), and the independence of an athlete is supported by Boggiano et al. (1993).

Another piece of support for autonomy supportive behaviours of coaches in a sport setting is provided by Pelletier et al. (200 I). They showed that perceived autonomy supportive behaviours of coaches were related to types of self-regulation, individuals who exhibit these types of self-regulation show more persistence than ones who do not. The importance of selfregulation is also supported by Abbott and Collins (2004). They found that self-regulated learning strategies can have a key role in positively facilitating the 
interaction of an athlete with his environment and enabling an athlete to fulfil his potential. Supplementary support for self-regulation is found in the academic domain, self-regulated learning is found to be a successful way to achieve good performance (Pintrich and De Groot, 1990, Boekaerts, 1999). Furthermore, high achievers use self-regulatory learning more often and more effectively than low achievers Zha (1993).

Finally, interviews with top level talent coaches revealed that they consider significant others. A poor negative correlation ( $r$ o $=-0,062 ; \mathrm{p}=$ 0,417 ) was found between degree of successfulness and considering significant others in the second part of this research. This contrast is not very striking, because top level talent coaches also stated that considering significant others was the least important feature with which talent coaches can contribute to the development of a talented athlete.

Top level talent coaches inform parents of talented athletes. Literature also suggests that talent coaches should educate parents of talented athletes about the role parents have (Gould et al., 2006). Top level talent coaches also take into consideration school and social life of talented athletes. To our knowledge no research is conducted on the importance of taking into consideration education and social life of a talented athlete by a talent coach. Top level talent coaches also used role models. Literature supports this, the utilization of role models is found to be important for talent development by Martindale et al. (2005). Although considering significant others seems to be an important feature with which a talent coach can contribute to the development of talented athletes, it seems to be the least important one and It does not seem to predict degree of successfulness of a talent coach.

\section{STRENGTH \& LIMITATIONS}

Several limitations exist in the method of approach. Although attempts were made to obtain honest responses from the talent coaches, it was possible for talent coaches to provide desirable answers. The data collected in the second part was collected in a retrospective fashion, results can therefore be subject to attribution effects and memory bias. This must be considered in interpreting the findings. Furthermore, It has to be taken into consideration that other people (athlete, parents etcetera) who play an important role in the functioning of a talent coach, have not been included in the first part of this study. Therefore, to obtain an even better picture, future research should incorporate the way in which talent coaches implement their coaching in practice. Athletes, parents and possible other significant people a talent coach works with should be included in further research as well. To obtain a current picture of features with which a talent coach can contribute to the 
development of talented athletes, the participants operated in different sports. As a result of this, not all talent coaches employed features in exactly the same way. Future research should detect a possible difference between various sports. A difference of features employed by top level talent coaches can also be expected from the kind of data used.

A limitation of the second part of this research was the interview guide, reliability and validity of the questions have never been investigated. Therefore, the reliability and validity of the interview guide needs to be investigated in further research. Furthermore, the way in which the degree of successfulness was operationalized is arbitrary. It depends for a large part on characteristics of the talented athletes. However, in our opinion no better measurable way of degree of successfulness exists, since a talent coach will always be dependent on the potential of his athletes.

This investigation had a number of strengths. First, the level of the studied talent coaches was very high. This results in a accurate picture of important features with which a talent coach can contribute to the development of a talented athlete. To make sure the participants were indeed top level talent coaches, the selection criteria were strict. A minor disadvantage of these strict criteria was the resulting small sample size.

Another strength of this research was the method of approach. This paper presents an innovative way of investigating important features with which a talent coach can contribute to the development of talented athletes by linking features of a talent coach with their degree of successfulness. With this new way of investigating talent coaches, it becomes possible to obtain a better understanding of important features of a talent coach for talent development.

Another strength of this research is the combination of qualitative as well as quantitative data. Outcomes from the qualitative data from the first part are examined by the quantitative data from the second part. This increases the importance which can be attached to the findings of this research (Foss and Ellefsen, 2002)

Consequently, top level talent coaches possess all features corresponding with available literature (education and experience, synchronization with developmental stages, goal setting, implementation motivational climate, autonomy supportive behaviour, and considering significant others) with which they can contribute to the development of talented athletes. Autonomy supportive behaviour and synchronization with developmental stages have the highest association with degree of successfulness and seem to be the most important features with which a 
talent coach can contribute to the development of talented athletes. Goal setting is associated with degree of successfulness to a lesser extent, although goal setting seems to be an important feature in the contribution to the development of talented athletes as well. Education and experience and motivational climate yet show more contradictory results, although it appears from the first part of this study and available literature that a talent coach can also contribute to the development of talented athletes with these features. Considering significant others seems to be the least important feature with which a talent coach can contribute to the development of talented athletes.

The outcomes of this research may optimize talent development by improving the knowledge of one of the important factors for talent development (talent coach). With this knowledge, the chance for talented athletes to reach elite level can be increased, by for example focusing on the important features with which a talent coach can contribute to the development of talented athletes in the training and selection of talent coaches.

\section{ACKNOWLEDGMENTS}

This study is conducted with cooperation of the Dutch Olympic Committee (NOC*NSF). We are grateful to all participants who cooperated with this study.

\section{REFERENCES}

Abbott A \& Collins D (2004). Eliminating the dichotomy between theory and practice in talent identification and development: considering the role of psychology. Journal of Sports Sciences, 22, 395-408.

Abbott A, Button C, Pepping GJ \& Collins D (2005). Unnatural selection: talent identification and development in sport. Nonlinear Dynamics, Psychology \& Life Sciences, 9, 61-88.

Abraham A, Collins D \& Martindale R (2006). The coaching schematic : Validation through expert coach consensus. Journal of Sports Sciences, 24, 549-564.

Balyi I, Cardinal Ch, Higgs C, Norris S \& Way R (not dated). Canadian sport for life: Long-term Athlete Development (Resource paper V2) Vancouver: Canadian Sport Centres, URL: http://www.sport.nl/content/pdf/207220/LTAD_E NG_66p_June5.pdf

Baker J, Horton S, Robertson-Wilson J \& Wall M (2003). Nurturing sport expertise: Factors influencing the development of elite athlete. Journal of Sports Science and Medicine, 2, I-9. 
Black AE \& Deci EL (2000). The effects of instructors' autonomy support and students' autonomous motivation on learning organic chemistry: A selfdetermination theory perspective. Science Education, 84, 740-756.

Bloom BS (1985). Developing Talent in Young People. New York: Ballantine.

Boekaerts M (1999) Self-regulated learning: where we are today. International journal of educational research, 31, 445-457.

Boggiano AK (1998). Maladaptive achievement patterns: a test of a diathesisstress analysis and helplessness. Journal of Personality and Social Psychology, 74, 1681-1695.

Boggiano AK, Flink C, Shields A, Seelbach A \& Barrett M (1993). Use of techniques promoting students' self-determination: effects on students' analytic problemsolving skills. Motivation and Emotion, 17, 319-336.

Boyce BA (1992). The Effects of Goal Proximity on Skill Acquisition and Retention of A Shooting Task in A Field-Based Setting. Journal of Sport \& Exercise Psychology, 14, 298-308.

Cordova DI \& Lepper MR (1996). Intrinsic motivation and the process of learning: beneficial effects of contextualization, personalization, and choice. Journal of Educational Psychology, 88, 7I 5-730.

Cote J (1999). The influence of the family in the development of talent in sport. Sport Psychologist, 13, 395-417.

Cote J, Baker J \& Abernethy B (2003). From play to practice. In Expert Performance in Sports: Advances in Research on Sport Expertise (Edited by Starkes, J.A. \& Ericsson, K.A.). Champaign, IL: Human Kinetics, pp 89-I I 4.

Cumming SP, Smoll FL, Smith RE \& Grossbard JR (2007). Is winning everything? The relative contributions of motivational climate and won-lost percentage in youth sports. Journal of Applied Sport Psychology, 19, 322-336.

Deci EL, Eghari H, Patrick BC \& Leon DR (1994). Facilitating internalization: the self-determination theory perspective. Journal of Personality, 62, I19142.

Dweck CS (1999). Self theories and goals: their role in motivation, personality, and development. Philidelphia: Taylor \& Francis.

Elferink-Gemser MT, Visscher C, Lemmink KAPM \& Mulder Th (2004). Relation between multidemensional performance characteristics and level of performance in talented youth field hockey players. Journal of Sports Sciences, 22, 1053-1063

Ericsson KA (2003). Development of elite performance and deliberate practice. In Expert Performance in Sports: Advances in Research on Sport Expertise (Edited by Starkes, J.A. \& Ericsson, K.A.). Champaign, IL: Human Kinetics, pp 49-84.

Foddy WH (1993) Constructing questions for interviews and questionnaires: theory and practice in social research. Cambridge: Cambridge University Press. 
Foss B \& Ellefsen B (2002). The value of combining qualitative and quantitative approaches in nursing research by means of method triangulation. Journal of Advanced Nursing, 40, 242-248.

Gould D, Gianni J, Krane V \& Hodge K (1990). Educational needs of elite U.S. National Team, Pan American, and Olympic coaches Journal of Teaching in Physical Education, 9, 332-344.

Gould D, Dieffenbach K \& Moffett A (2002). Psychological characteristics and their development in Olympic champions. Journal of Applied Sport Psychology, 14, 172-204.

Gould D, Lauer L, Rolo C, Jannes C \& Pennisi N (2006). Understanding the role parents play in tennis success: a national survey of junior tennis coaches. British Journal of Sports Medicine, 40, 632-636.

Helsen WF, Hodges NJ, Van Winckel J \& Starkes JL (2000) The roles of talent, physical precocity and practice in the development of soccer expertise. Journal of Sports Sciences, 18, 727-736.

Howe MJA, Davidson JW \& Sloboda JA (1998). Innate talents: Reality or myth. Behavioral and Brain Sciences, 21, 399-442.

Koestner R, Ryan RM, Bernieri F \& Holt K (1984). Setting limits on children's behaviour: the differential effects of controlling versus informational styles on intrinsic motivation and creativity Journal of Personality, 52, 233-248.

King N (1998) Template analysis. In Qualitative Methods and Analysis in Organizational Research. (Edited by G. Symon and C. Cassell) London: Sage, pp | | 8- | 34 .

Kyllo LB \& Landers DM (1995). Coal Setting in Sport and Exercise - A Research Synthesis to Resolve the Controversy. Journal of Sport \& Exercise Psychology, 17, 1 17-137.

Lemyre F, Trudel P \& Durand-Bush, N (2007). How youth-sport coaches learn to coach. Sport Psychologist, 21, 191-209.

Lyle J (2002) Sports coaching concepts : a framework for coaches' behaviour. London [etc.]: Routledge.

Mageau GA \& Vallerand RJ (2003). The coach-athlete relationship: a motivational model. Journal of Sports Sciences, 21 , 883-904.

Martindale RJJ, Collins D \& Abraham A (2007). Effective talent development: The elite coach perspective in UK sport. Journal of Applied Sport Psychology, 19, 187-206.

Martindale RJJ, Collins D \& Daubney J (2005). Talent development: A guide for practice and research within sport. Quest, 57, 353-375.

Mooney RP \& Mutrie N (2000). The effects of goal specificity and goal difficulty on the performance of badminton skills in children. Pediatric Exercise Science, 12, 270-283.

Morgan TK \& Giacobbi PR (2006). Toward two grounded theories of the talent development and social support process of highly successful collegiate athletes. Sport Psychologist, 20, 295-313. 
Naughton G, Farpour-Lambert NJ, Carlson J, Bradney M \& Van Praagh E (2000). Physiological Issues Surrounding the Performance of Adolescent Athletes. Sports Medicine, 30, 309-325.

Ntoumanis, $N$ \& Biddle, S.J.H. (1999). A review of motivational climate in physical activityJournal of Sports Sciences, 17, 643-665.

Ommundsen Y \& Kvalø SE (2007). Autonomy-Mastery, Supportive or Performance Focused? Different teacher behaviours and pupils' outcomes in physical education. Scandinavian Journal of Educational Research, .5I, 385$4 \mid 4$.

Pelletier LG, Fortier MS, Vallerand RJ \& Briere NM (200I). Associations Among Perceived Autonomy Support, Forms of Self-Regulation, and Persistence:A Prospective Study. Motivation and Emotion, 25, 279-306.

Pensgaard AM, \& Roberts GC (2002). Elite athletes' experiences of the motivational climate: The coach matters. Scandinavian Journal of Medicine \& Science in Sports, 12, 54-59.

Pintrich PR \& De groot EV (1990). Motivational and Self-Regulated Learning Components of Classroom Academic-Performance. Journal of Educational Psychology, 82, 33-40.

Singer RN \& Janelle CM (1999). Determining sport expertise: From genes to supremes. International Journal of Sport Psychology, 30, II 17 - 150.

Smith RE, Smoll FL \& Cumming SP (2007). Effects of a motivational climate intervention for coaches on young athletes' sport performance anxiety. Journal of Sport \& Exercise Psychology, 29, 39-59.

Söderman P \& Malchau H (200I) Is the Harris hip score system useful to study the outcome of total hip replacement. Clinical Orthopaedics and related Research, 384, I89-197.

Weinberg RS (1994). Goal-Setting and Performance in Sport and Exercise Settings - A Synthesis and Critique. Medicine and Science in Sports and Exercise, 26, 469-477.

Weinberg R, Butt J \& Knight B (200 I). High school coaches' perceptions of the process of goal setting. Sport Psychologist, 15, 20-47.

Widmeyer WN \& Ducharme K (1997). Team building through team goal setting. Journal of Applied Sport Psychology, 9, 97-I 13.

Williams AM \& Reilly T (2000). Talent identification and development in soccer. Journal of Sports Sciences, 18, 657-667.

Wilmore JH, Costill DL \& Kenny WL (2008). Physiology of sport and exercise. Champaign, IL: Human Kinetics.

Zha Z (1993). Programs and practices for identifying and nurturing giftedness and talent in People's Republic of China. In Internatioal handbook of research and development of Giftedness and Talent (Edited by K. Heller, F.J. Monks and A. H. Passow). Oxford: Pergamon Press, pp 809-8।4. 
Série

Investigação

Imprensa da Universidade de Coimbra

Coimbra University Press

2010

- U r

C • 